coloproctology $2017 \cdot 39: 179-183$

DOI 10.1007/s00053-016-0133-0

Published online: 8 February 2017

๑) Springer Medizin Verlag Berlin 2017

CrossMark

\author{
W. Kneist ${ }^{1} \cdot$ S. Stelzner ${ }^{2} \cdot$ F. Aigner ${ }^{3} \cdot$ A. Fürst ${ }^{4} \cdot$ T. Wedel $^{5}$ \\ ${ }^{1}$ Department of General, Visceral and Transplant Surgery, University Medicine of the Johannes \\ Gutenberg-University Mainz, Mainz, Germany \\ ${ }^{2}$ Department of General and Visceral Surgery, Dresden-Friedrichstadt General Hospital, Dresden, Germany \\ ${ }^{3}$ Department of Surgery, Charité - University Medicine Berlin, Campus Virchow, Berlin, Germany \\ ${ }^{4}$ Department of Surgery, Caritas-Hospital St. Josef, Regensburg, Germany \\ ${ }^{5}$ Center of Clinical Anatomy, Institute of Anatomy, Christian-Albrechts University of Kiel, Kiel, Germany
}

\title{
Urethral injury in body donor TaTME training
}

\section{Methods}

We carried out a 2-day TaTME body donor training workshop at the Center of Clinical Anatomy, Christian Albrecht University of Kiel, Germany. This specialized training course was designed to address the specific surgical challenges that arise during TaTME and comprised the following modules:

\section{1) Theoretical module}

[2]. The cumulative morbidity rate is reportedly $6.3 \%$ in male patients [3-7]. In the international TaTME registry, the rate of urethral injuries in males was 1\% (5/489) [8]. However, a voluntary registry could underestimate the risk.

There are only few recent data available regarding risk factors and optimal techniques to avoid or effective options to treat such injuries. However, a recent international inquiry regarding TaTMEassociated urologic injuries yielded a considerably high number $(n=32)$ of incidents (Patricia Sylla, personal communication 2016 Nov 28).

Because of the novel and unusual approach of TaTME and the increased risk of urethral injuries, a recent report proposed that one of the core elements of TaTME educational programs should be surgical training sessions in human body donor models [9]. In this report, we present effective educational modules offered in a body donor workshop, illustrating how to take full advantage of this type of preclinical training course in order to prevent urethral injury during TaTME.
The theoretical module started with lectures on the topographic anatomy, emphasizing the crucial anatomic landmarks to be respected during the transanal approach. Special focus was given to the close proximity of the distal prostatic and membranous part of the urethra to the anterior rectal wall and the perineal body. Lectures on the clinical evidence, stepwise surgical techniques, and common pitfalls of TaTME completed the session. A video demonstration of an inadvertent urethral injury was presented and discussed in detail by the participants.

\section{2) Practical module-predissected specimens}

Predissected formalin-fixed anatomical pelvic topography by means of a video system projecting the anatomical details on large flatscreen high-definition monitors. The specimens had been dissected by both a clinical anatomist (TW) and specimens were used to demonstrate the a surgeon (SS) to specifically address those anatomical features relevant for TaTME (• Fig. 1). While the clinical anatomist described the macroscopic structures in general, the faculty translated the anatomical remarks into the surgical context of TaTME procedure. After the demonstration, all participants were requested to perform a hands-on study of the predissected specimens by themselves.

\section{3) Practical module-simulators}

Practical exercises were performed in an augmented virtual environment (Simsei Laparoscopic Trainer; Applied Medical, Rancho Santa Margarita, CA, USA). The faculty proctored correct placement of the transanal access platform and pursestring suturing (- Fig. 2a). Incorrect handling of either the transanal access platform or dislocated purse-string sutures were discussed by the participants and repeated until optimal results were achieved.

\section{4) Practical module-TaTME procedure performed in body donors}

Under the guidance of the faculty, the participants performed TaTME in four male body donors (- Fig. 2b, c). A maximum of three participants were allocated to one working station. This module highlighted the team approach with instruction comprising standardized verbal feedback for instrument handling. It also 


\section{Übersichten}
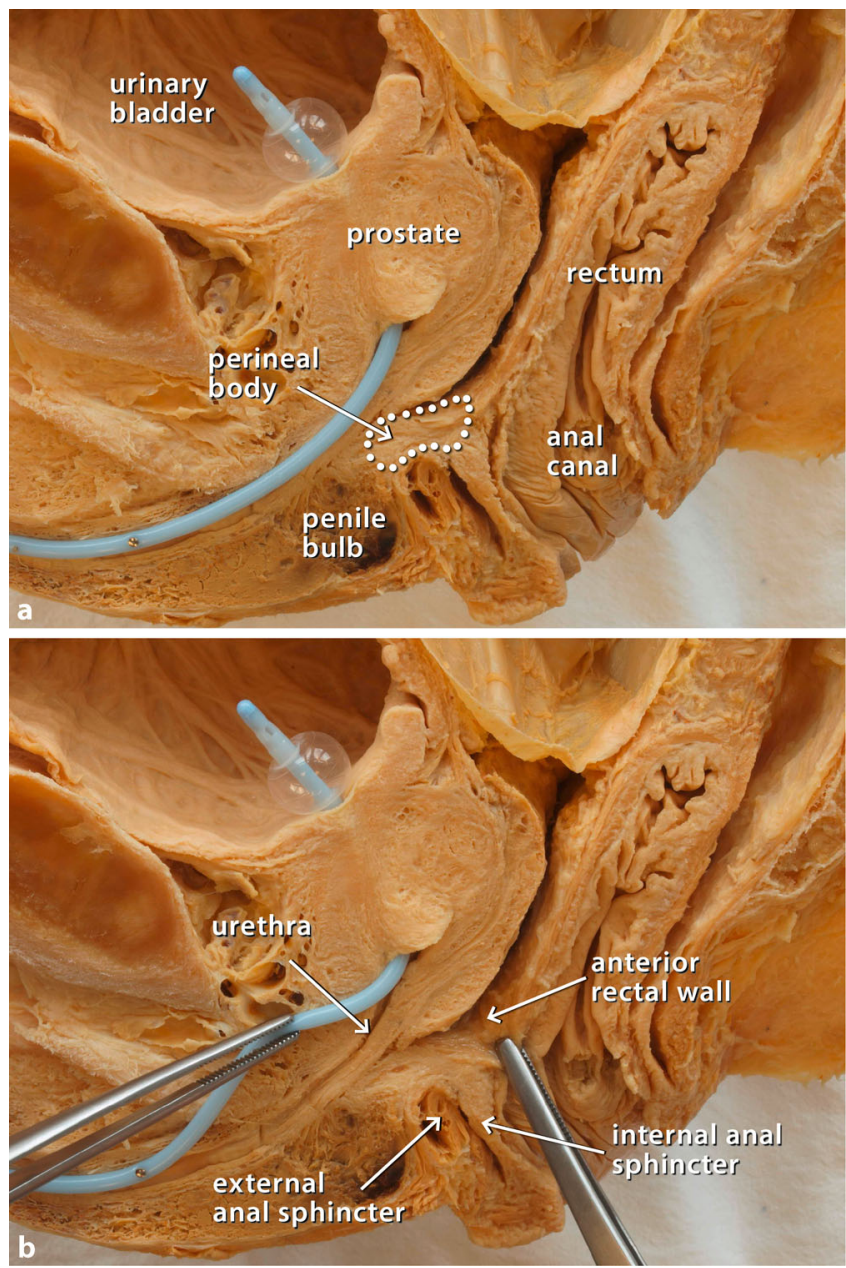

Fig. $1 \Delta$ Predissected anatomical specimen of a right male hemipelvis used for live demonstration, hands-on study, and discussion prior to the proper transanal mesorectal excision (TaTME) procedure. The course of the urethra is indicated by an inserted urinary catheter. The perineal body is firmly connected anteriorly to the prostatic apex and membranous urethra, and posteriorly to the anterior rectal wall and external anal sphincter. The close proximity of the membranous urethra to the anterior dissection plane illustrates and explains the increased risk of urethral injury during TaTME

addressed potential methodical and psychological issues [9]. The body donors were embalmed previously by modified ethanol glycerin fixation and stored at $4^{\circ} \mathrm{Cbefore}$ use [10]. Each bodydonor was placed in the appropriate Lloyd-Davies position on a mobile operating table (Maquet $\mathrm{GmbH}$, Rastatt, Germany). Prior to the intervention, a 16 French gauge Foley urinary catheter was inserted into the urinary bladder via the urethra and blocked. A Lone Star retractor (CooperSurgical, Trumbull, CT, USA) and GelPOINT Path Transanal Access Platform (Applied Medical) were inserted to gain optimal exposure of the rectal lumen. After purse-string suture at the level of the
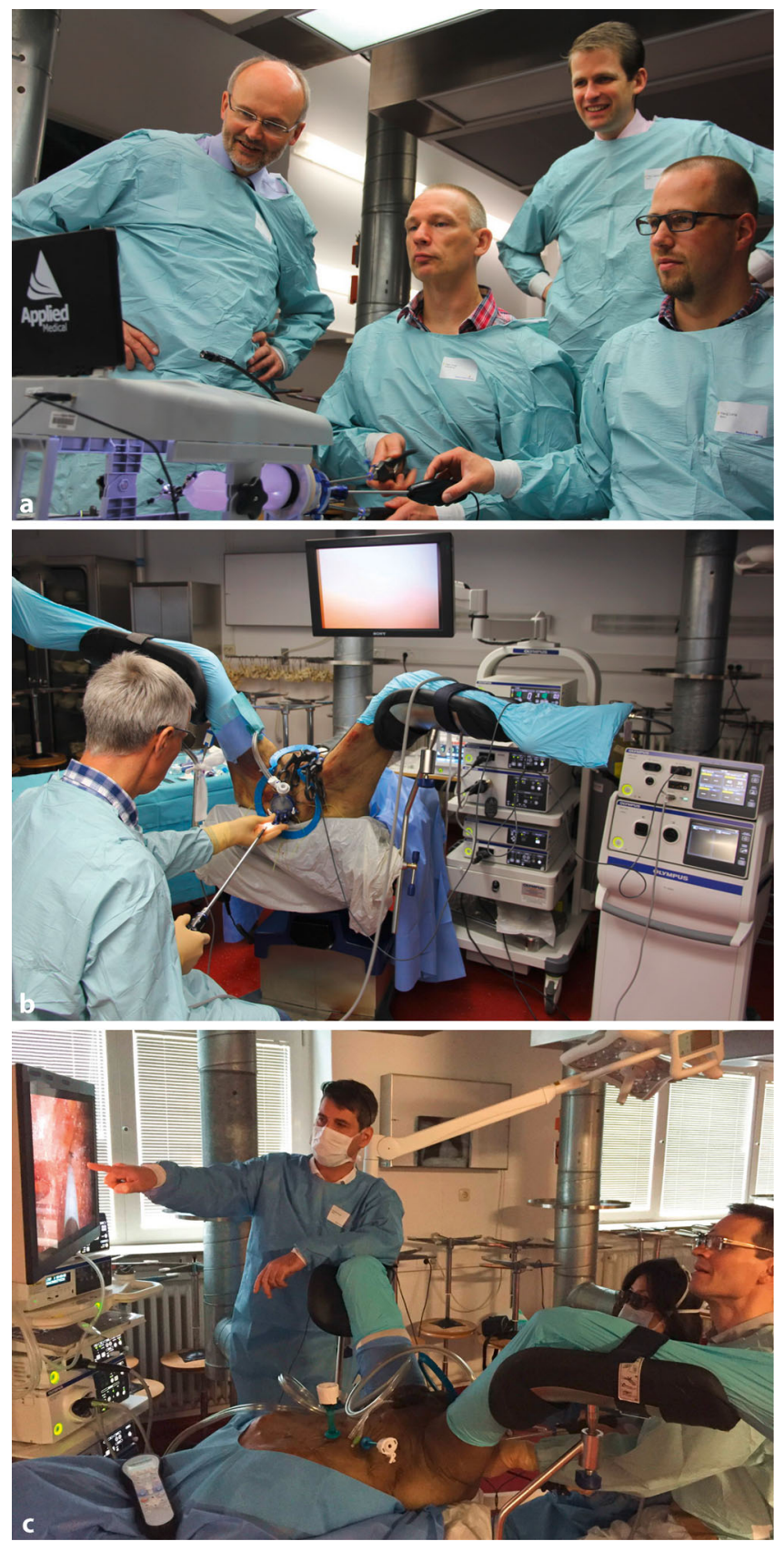

Fig. $2 \Delta$ a Practical module using a simulator for correct placement of the transanal access platform and purse-string suturing of the rectal wall.b Practical module using male body donors for proctored transanal mesorectal excision (TaTME). The operative setup included a mobile operating table, laparoscopy tower, energy devices, Lone Star retractor (CooperSurgical, Trumbull, CT, USA), transanal access platform coupled to an insufflation device. c Practical module with one-on-two instruction implying intentional urethral injury and mobilization of prostate (๑ The authors)

distal rectum, circumferential full-thickness incision of the rectal wall was carried out $1.5 \mathrm{~cm}$ above the dentate line with a monopolar hook. An angled laparoscope $(10 \mathrm{~mm}$ diameter; Olympus Europa SE \& Co. KG, Hamburg, Germany) was used during the procedure and $\mathrm{CO}_{2}$ was continuously insufflated at a pressure of $12 \mathrm{~mm} \mathrm{Hg}$ (AirSeal; SurgiQuest, Milford, CT, USA). Transanal mesorectal mobilization was performed with the monopolar hook. Subperitoneal dissec- 
coloproctology 2017 · 39:179-183 DOI 10.1007/s00053-016-0133-0

(c) Springer Medizin Verlag Berlin 2017

W. Kneist · S. Stelzner · F. Aigner · A. Fürst · T. Wedel

\section{Urethral injury in body donor TaTME training}

\section{Abstract}

Background. Urethral injury is one of the major risks in transanal total mesorectal excision (TaTME). To provide surgeons with experience in and management of potential critical surgical scenarios, urethral and prostate injuries were intentionally created during a body donor workshop under standardized training conditions.

Methods. We conducted a 2-day structured TaTME body donor training workshop. The theoretical module included lectures on topographic anatomy, clinical evidence, and surgical technique and pitfalls. Practical modules started with an interactive demonstration of crucial landmarks for the transanal approach using predissected formalin-fixed specimens. Next, surgical teams underwent proctored surgical training that implemented the key steps of TaTME on simulators and four male body donors. Strategies to avoid urethral damage involved intentional dissection and injury of the urethra and prostate, with subsequent demonstration of these lesions. Results. After emphasizing the critical anatomical landmarks, the proctored surgical teams performed TaTME successfully without any urethral lesions. To demonstrate worst-case scenarios, two major pitfalls associated with TaTME, i.e., urethral injury and mobilization of the prostate, were simulated. These deliberate injuries proved to be critical learning experiences for all participants.
Conclusion. Appraisal of crucial anatomical landmarks and deliberate implementation of urethral/prostatic injury scenarios in preclinical TaTME training workshops is an effective way to teach surgeons how to avoid those injuries in patients. Structured and supervised training should be offered to all surgeons prior to implementing TaTME procedures in order to acquire skills necessary to address the delicate structures at risk during transanal approach.

Keywords

Rectal cancer - Transanal minimally invasive surgery - Transanal total mesorectal excision . Anatomy · Surgical education · Urethra

\section{TaTME-Training an Körperspendern mit Verletzung der Urethra}

\section{Zusammenfassung}

Hintergrund. Die Verletzung der Urethra ist ein eingriffsspezifisches Risiko bei der transanalen total mesorektalen Exzision (TaTME). Um Chirurgen für diese intraoperative Komplikation zu sensibilisieren, wurden die kritischen Operationsabschritte standardisiert besprochen und am Körperspender trainiert sowie Urethra- und Prostataverletzungen absichtlich herbeigeführt.

Methode. In einem 2-tägigen strukturierten TaTME-Operationskurs an Körperspendern wurden die topographische Anatomie, klinische Evidenz, chirurgische Technik und Fehlermöglichkeiten besprochen. Die praktischen Übungen an formalinfixierten Beckenpräparaten beinhalteten die interaktive Demonstration der wichtigen Landmarken für den transanalen Zugangsweg. Beim angeleiteten operativen Teamtraining wurden die Schlüsselschritte des transanalen Vorgehens an Simulatoren und an 4 männlichen Körperspendern geübt. Nach Vermittlung von Strategien zur Vermeidung von Urethraverletzungen wurden später zur Verdeutlichung der Topographie Urethra- und Prostataverletzungen bewusst zugelassen. Ergebnisse. Nach Identifizierung der kritischen anatomischen Landmarken absolvierten die angeleiteten Teams die transanale TME erfolgreich ohne Verletzung der Urethra. Zur Demonstration schwerwiegender Komplikationen wurde die Verletzung der Urethra und die Mobilisation der Prostata herbeigeführt. Die Simulation der Komplikationen erwies sich für alle
Kursteilnehmer als wichtige Möglichkeit, um den Lerneffekt zu maximieren.

Schlussfolgerung. Die Beurteilung der kritischen anatomischen Landmarken und die bewusste Implementierung von Urethraund Prostataverletzungen in präklinischen TaTME-Operationskursen zeigen effektiv, wie Chirurgen solche Verletzungen vermeiden können. Das Absolvieren solcher strukturiert angeleiteter Kurse ist daher dringend zu empfehlen, bevor die TaTME in der Klinik implementiert wird.

\section{Schlüsselwörter}

Rektumkarzinom · Transanale minimalinvasive Chirurgie - Transanale totale mesorektale Exzision - Anatomie - Chirurgische Weiterbildung · Urethra tion of the mesorectal fascia started dorsolaterally until reaching the level of S2-3 and was completed anteriorly up to the rectovesical pouch. The abdominal part of the procedure was carried out by multiport laparoscopy and included mobilization of the sigmoid colon and mesorectal pedicle. The peritoneal fold was completely opened, and total mesorectal dissection was finished by a dorsolateral rendezvous.

\section{5) Practical module-intentional urethral injury and mobilization of prostate}

In a final step, the ventral surgical plane of TaTME was further dissected to expose the membranous urethra and the apex and dorsal aspect of the prostate. Participants were guided to deliberately incise and open the urethral lumen until the urinary catheter was visible and to mobilize the prostate in one of the cadavers (- Fig. 3). The urethral injury and the topographic anatomy were demonstrated in detail, discussed by the entire group, and carefully documented for a debriefing session.

\section{Results}

A key role of the proctored training course on TaTME was the inclusion of predissected anatomical specimens to highlight the intimate relationship between the anorectum, prostate, and urethra. While anatomical textbooks suggest that the distance between these structures is sufficient to avoid injuries, 

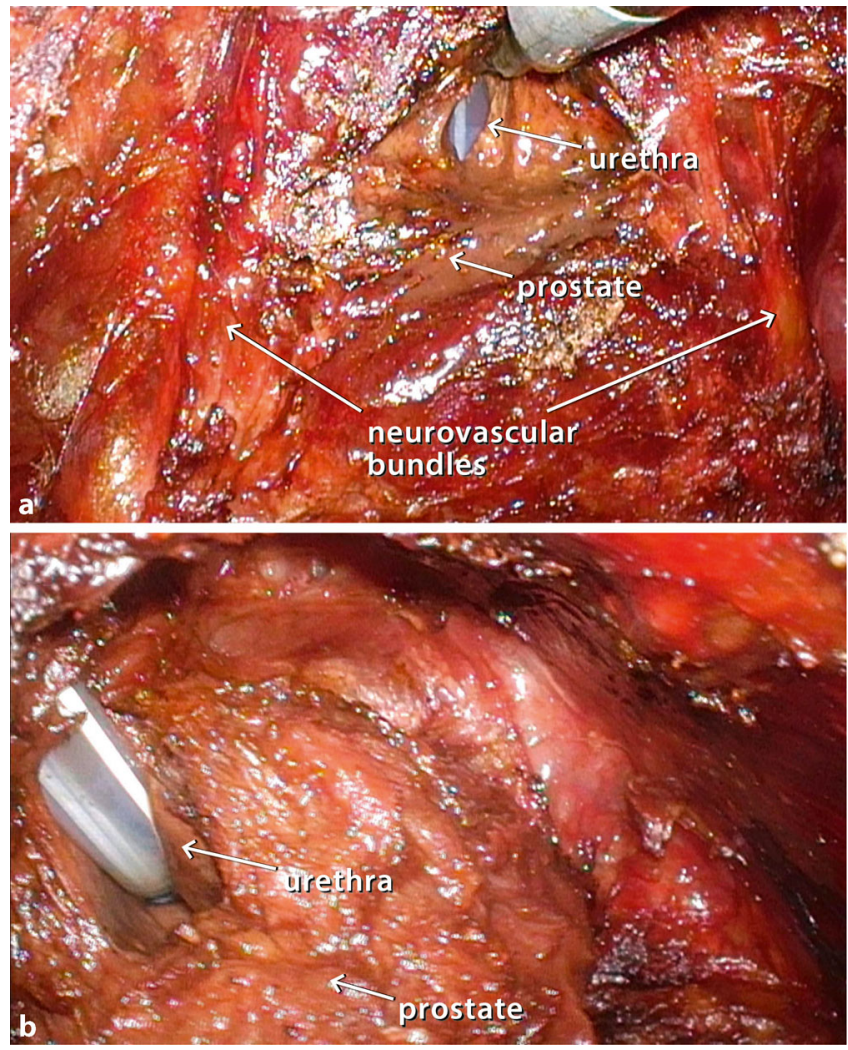

Fig. $3<$ a Intraoperative situs after deliberate injury of the urethra. The correct ventral dissection plane is still exposed, but was left in anterolateral direction to intentionally injure the urethra. Only a few diathermy dissection steps were required to expose the inserted urinary catheter. Note the neurovascular bundles of Walsh. b Intentional exposure of the posterolateral aspects of the prostate during the bottom-up approach

the specimens clearly illustrated that particularly the membranous part of the urethra and the apex of the prostate are separated from the anterior rectal wall only by the perineal body (• Fig. 1). Moreover, this peculiar region does not exhibit clearly defined surgical planes and, thus, requires sharp dissection to mobilize the rectum anteriorly. Based on these anatomical demonstrations and hands-on studies by the participants, the faculty could convincingly emphasize that this area should be considered as a high-risk zone for urethral damage during TaTME.

Working in small teams, the participants completed TaTME in four body donors without causing any urethral lesions. Each of the participants was then given the opportunity to produce an accidental injury to the membranous urethra in one of the cadavers. First, the proctor pulled out the flexible transanal port to expose the level of incision that had been made previously through the juxta-anal rectal wall. Second, he immediately caused a steep upward slope of the transanal access platform. This extreme exposition of the anterior plane near the perineal body is a common source of error. Using the monopolar hook, the anterior plane could now be easily breached, and after only a few dissection steps injury of the membranous urethra became obvious (• Fig. 3a).

While the participants performed the transanal mesorectal dissection under strictly guided and controlled conditions, during the final practical module the participants were allowed to intentionally leave the anterior dissection plane created previously and to deliberately mobilize the prostate. Dissection was carried out in anterolateral direction at the 10 and 2 oclock positions to expose the apex and dorsolateral aspects of the prostate (• Fig. 3b). These intentional errors effectively demonstrated that deflection of the prostate gland can occur during TaTME, and it should be avoided assiduously.

\section{Discussion}

Although urethral injuries are rarely observed during laparoscopic resection for rectal cancer [11], accidental intraoperative injuries to the urethra and prostate occur relatively often during TaTME. These types of injuries during TaTME are particularly specific to male patients, although case selection and differences in learning curves may have led to the preponderance of reported complications in men [12]. Because of the considerable risk of complications associated with TaTME in men, providing an effective and supervised training from the beginning appears to be necessary. Performing injury-free TaTME is a challenge faced by all those involved in performing this procedure [13].

A thorough TaTME training program would ideally include a comprehensive presentation of common pitfalls gleaned from the literature and from the instructors' own experiences. In this context, the most effective benefit for the participants was achieved by a two-fold didactic approach prior to the proper TaTME procedure: (1) to display and discuss video clips recorded from cases in which such pitfalls occurred; (2) to give the opportunity to master topographical spatial orientation in regards to the surgical planes encountered during TaTME by the demonstration and hands-on study of predissected anatomical specimens.

As with abdominoperineal rectal excision [14], the bottom-up approach creates an artificial dissection plane through the perineal body with close proximity to the membranous urethra and the anterior quadrant of the rectum. It should be noted that expansion of the anal canal by the transanal access platform, as well as an excessively steep position or a pursestring suture that is stitched too deeply ventrally, can increase the likelihood of injury to the membranous urethra. Others shared their experience with TaTME in patients with narrow male pelvis and bulky pelvic musculature. This constellation is liable to elongate membranous urethra, resulting in a higher risk of injury [15]. Further risks include anterior quadrant involvement of distal rectal cancer and distorted tissue planes due to radiotherapy or variations of the normal anatomy, e. g., benign prostatic hyperplasia, and previous urologic treatment, e. g., transurethral resection of the prostate.

A body donor training workshop might also be an optimal strategy for 
well-trained colorectal surgeons who want to familiarize themselves with this new approach. We found that in our training session, even experienced senior surgeons with advanced laparoscopic skills appreciated the chance to discuss potential failures with clinically oriented anatomists and to demonstrate and highlight these surgical pitfalls by means of predissected anatomical specimens. Based on our experience with the training modules as described above, we believe that using human body donors in an operating room scenario can provide surgeons with effective, structured, and real-time training in TaTME in a secure environment. Atallah et al. recently reported good results yielded by $>100$ surgeons who were trained to perform TaTME. During a hands-on session with body donors, they observed inadvertent mobilization of the prostate by $20 \%$ of the surgical teams [16]. The participants in our educational TaTME modules completed the procedure without any complications, which was one of the main objectives of the exercise.

However, surgeons have indicated that having prior experience with injuries and complications this type from training workshops has further improved their performance during critical situations. Since neither prostate exposure nor urethral injury occurred spontaneously in any of the proctored TaTME cases, the decision was made to include a simulation and analysis of surgical complications as a mandatory part of the training program. Intentional urethral injury and mobilization of the prostate were accordingly carried out to illustrate how easily these complications could occur during TaTME. We believe that a demonstration of how such injuries can come about during TaTME is an important educational tool that provides participants with valuable experience prior to starting case observations and their own surgical practice. It should be a key element of skill acquisition during supervised TaTME training.

\section{Conclusion}

Demonstration of worst-case scenarios during comprehensive body donor work- shops are a prerequisite to alert surgeons to major complications in recently introduced surgical techniques. In TaTME, this applies to inadvertent urethral injury, which can be integrated in body donor training in order to establish strategies to avoid it. This may translate into a reduction of this kind of complication during further introduction of TaTME to the surgical community on a broader base.

\section{Corresponding address}

\section{Prof. Dr. med. W. Kneist}

Department of General, Visceral and Transplant Surgery, University Medicine of the Johannes Gutenberg-University Mainz

Langenbeckstraße 1, 55131 Mainz, Germany werner.kneist@unimedizin-mainz.de

Acknowledgements. The authors thank Stefanie Gundlach (anatomical dissector), Arndt Gundlach (technical assistant), and Thomas Benecke (technical assistant) at the Institute of Anatomy for their technical support. We also wish to thank Prof. Dr. M. Biebl, Priv.-Doz. Dr. A. D. Rink, and Dr. H. Aselmann for their close collaboration with the faculty. Finally, we wish to thank Olympus Medical Systems, Maquet $\mathrm{GmbH}$, Surgiquest, Applied Medical, and DACH medical group for equipment loan.

Funding. The training course was funded by an educational grant from Olympus Medical Systems.

\section{Compliance with ethical guidelines}

Conflict of interest. The training course was funded by an educational grant from Olympus Medical Systems and was under the patronage of the colorectal surgery working group of the German Society of General and Visceral Surgery (DGAV). W. Kneist, S. Stelzner, F. Aigner, A. Fürst, and T. Wedel declare that they have no competing interests.

All procedures complied with the ethical standards and regulations for the use of human body donors obtained by the body donation program at the Institute of Anatomy, University of Kiel, Germany.

\section{References}

1. Chand M, Moran B, Wexner S (2016) Which technique to choose in the high-tech era of minimal-access rectal cancer surgery? Colorectal Dis 18:839-841

2. Monson JR, Arsalanizadeh R (2016) Transanal total mesorectal excision (TaTME) and quality of rectal cancer surgery: Do we really know? Ann Surg. doi:10.1097/SLA.0000000000001736

3. Rouanet $P$, Mourregot A, Azar CC, Carrere $S$, Gutowski M, Quenet F, Saint-Aubert B, Colombo PE (2013) Transanal endoscopic proctectomy: an innovative procedure for difficult resection of rectal tumors in men with narrow pelvis. Dis Colon Rectum 56:408-415

4. Schirnhofer J, Brunner E, Mittermair C, Pimpl K, Obrist C, Waldstein N, Weiss HG (2014) Technical issues in transanal minimal invasive surgery: total mesorectal excision (TAMIS-TME). EurSurg 46:S58

5. Rink AD, Kauff DW, Paschold M, Vestweber K-H, Lang H, Kneist W (2016) Hybrid-TAMIS totale mesorektale Exzision. Chirurg 87:225-232

6. Kang L, Chen W-H, Luo S-L, Luo Y-X, Liu Z-H, Huang M-J, Wang J-P (2016) Transanal total mesorectal excision for rectal cancer: a preliminary report. Surg Endosc 30:2552-2562

7. Burke JP, Martin-Perez B, Khan A, Nassif G, de Beche-Adams T, Larach SW, Albert MR, Atallah $S$ (2016) Transanal total mesorectal excision for rectal cancer: early outcomes in 50 consecutive patients. Colorectal Dis 18:570-577

8. Penna M, Hompes R, Arnold S, Wynn G, Austin R, Warusavitarne J, Moran B, Hanna GB, Mortensen NJ, Tekkis PP, TaTME Registry Collaborative (2016) Transanal total mesorectal excision: international registry results of the first 720 cases. Ann Surg. doi: $10.1097 /$ SLA.0000000000001948

9. McLemore EC, Harnsberger CR, Broderick RC, Leland H, Sylla P, Coker AM, Fuchs HF, Jacobsen GR, Sandler B, Attaluri V, Tsay AT, Wexner SD, Talamini MA, Horgan S (2016) Transanal total mesorectal excision (taTME) for rectal cancer: a training pathway. Surg Endosc 30:4130-4135

10. Paschold M, Huber T, Zeißig SR, Lang H, Kneist W (2014) Tailored instructor feedback leads to more effective virtual-reality laparoscopic training. Surg Endosc 28:967-973

11. Hammer N, Löffler S, Feja C, Sandrock M, Schmidt W, Bechmann I, Steinke H (2012) Ethanolglycerin fixation with thymol conservation: a potential alternative to formaldehyde and phenolembalming. Anat Sci Educ 5:225-233

12. Ng KH, Ng DC, Cheung HY, Wong JC, Yau KK, Chung CC, Li MK (2009) Laparoscopic resection for rectal cancers: lessons learned from 579 cases. Ann Surg 249:82-86

13. Atallah S, Albert M (2016) The neurovascular bundle of Walsh and other anatomic considerations crucial in preventing urethral injury in males undergoing transanal total mesorectal excision. Tech Coloproctol 20:411-412

14. Penna M, Hompes R, Mackenzie H, Carter F, Francis NK (2016) First international training and assessment consensus workshop on transanal totalmesorectal excision (taTME). Tech Coloproctol 20:343-352

15. Stelzner S, Holm T, Moran BJ, HealdRJ, Witzigmann H, Zorenko D, Wedel T (2011) Deep pelvic anatomy revisted for description of crucial steps in extralevator abdominoperineal excision for rectal cancer. Dis Colon Rectum 54:947-957

16. Marecik SJ, Pai A, Sheikh T, Park JJ, Prasad LM (2016) Transanal total mesorectal excision: save the nerves and urethra. Dis Colon Rectum 59:e410-e414. doi:10.1097/ DCR.0000000000000626

17. Atallah S, Albert M, Monson JR (2016) Critical concepts and important anatomic landmarks encountered during transanal total mesorectal excision (taTME): toward the mastery of a new operation for rectal cancer surgery. Tech Coloproctol 20:483-494 